\title{
CENÁRIO DA INSERÇÃO DE PESSOAS COM DEFICIÊNCIA NO MERCADO DE TRABALHO: REVISÃO SISTEMÁTICA
}

\author{
Aline Pereira RIBEIRO ${ }^{1}$ \\ Dirceu Fernandes BATISTA ${ }^{2}$ \\ José Marcos do PRADO ${ }^{3}$ \\ Kênia Eliber VIEIRA ${ }^{4}$ \\ Regiane Luz CARVALHO 5
}

\begin{abstract}
${ }^{1}$ Graduada em Letras UNIFEG, Especialista em Práticas Pedagógicas UFOP, Mestranda em Desenvolvimento Sustentável e Qualidade de Vida UNIFAE, Técnica em Assuntos Educacionais UNIFAL-MG. alineribeiro.45@gmail.com

${ }^{2}$ Graduado em Administração UNIFEOB, Especialista em Gestão Empresarial UNIFEOB, Mestrando em Desenvolvimento Sustentável e Qualidade de Vida UNIFAE, Professor de Administração UNIFEOB. dirceufbatista@hotmail.com

${ }^{3}$ Graduado em Ciências Contábeis UNIFAE, Especialista em Controladoria e Auditoria UNIFAE, Mestrando em Desenvolvimento Sustentável e Qualidade de Vida UNIFAE, Professor UNIFAE e UNIFEOB. marcosprado@ fae.br ${ }^{4}$ Graduada em Ciências Biológicas, FEM, Especialista em Direito Educacional FIJ, Mestranda em Desenvolvimento Sustentável e Qualidade de Vida UNIFAE, Técnica em Assuntos Educacionais UNIFAL-MG. keniaeliber@gmail.com ${ }^{5}$ Graduada em Fisioterapia, Mestre e Doutora em Neurofisiologia UNICAMP, Pós Doutora em Bioengenharia USP, Professora do Mestrado em Desenvolvimento Sustentável e Qualidade de Vida e curso de fisioterapia. egianeluzcarvalho@gmail.com
\end{abstract}

Recebido em: 30/05/2014 - Aprovado em: 15/09/2014 - Disponibilizado em: 15/12/2014

\begin{abstract}
Resumo
Apesar de as pessoas com deficiência terem por lei o direito de acesso ao mercado de trabalho, muitas dificuldades e barreiras ainda são enfrentadas por este grupo devido às práticas sociais atuais. Em virtude desta situação paradoxal, este artigo objetivou verificar o panorama brasileiro da inserção das pessoas com deficiência no mercado de trabalho, analisando se a força da lei tem, de fato, papel inclusivo. Trata-se de uma revisão de literatura sobre a temática inclusão no mercado de trabalho realizada através de consulta nas bases de dados SciELO, BIREME, LILACS e CAPES. Considerando os critérios de inclusão e exclusão estabelecidos, foram selecionados 20 artigos, cujos resultados compuseram a amostra deste estudo e subsidiaram as análises posteriores. Os resultados evidenciaram que somente a proteção legal não é capaz de incluir efetivamente as pessoas com deficiência no mercado de trabalho. Verificou-se também que a maioria das empresas contrata pessoas com deficiência apenas para cumprir a legislação, não tendo consciência da função social do trabalho. Assim, para que a inclusão realmente ocorra é imprescindível que haja um processo bilateral, no qual a sociedade ofereça condições para que as pessoas com deficiência exerçam a sua cidadania, com direitos a serem preservados e deveres a serem cumpridos, e as pessoas com deficiência busquem maior autonomia, independência a fim de que consigam participar ativamente da sociedade.
\end{abstract}

Palavras-chave: Pessoa com Deficiência, Integração, Inclusão, Trabalho.

\begin{abstract}
Although people with disabilities have by law the access to the labor quaranteed, many difficulties and barriers are still faced by this group due to current social practices. Because of this paradox, this article intends to check the Brazilian scenario of integrating people with disabilities into the labor market, analyzing the force of the law has, in fact, inclusive role. This is a systematic review of the scientific production contained in the databases SciELO, BIREME, LILACS and CAPES data and published after the implementation of the call Quota Law (Law no . 8.213/91). Considering the criteria for inclusion and exclusion set, it selected 20 articles whose results comprised the study sample and subsidized further analysis. The results of this review show that only legal protection is not able to effectively include people with disabilities in the labor market. It also appears that most companies hire people with disabilities only to fulfill the law, not being aware of the social function of work. So for that inclusion does occur it is essential that there is a bilateral process in which society provides conditions for people with disabilities to exercise their citizenship, with rights to be preserved and duties to be fulfilled, and people with disabilities seek greater autonomy, independence and empowerment, so that they can actively participate in society.
\end{abstract}

Keywords: People with Disabilities. Integration. Inclusion. Labour. 


\section{Introdução}

O trabalho tem importante repercussão na vida de todos os indivíduos e é apontado como atividade fundamental para a realização pessoal, desenvolvimento da auto-estima, interação social, sentimento de pertinência e capacidade, bem como construção de identidade e autonomia (NETTO, 2003). Considerando estes aspectos as políticas públicas têm dado especial atenção às propostas que buscam promover a participação e inclusão dos indivíduos com deficiência no mercado de trabalho.

Apesar da importância social do trabalho e embora a própria Constituição Federal (1988) defina em seu artigo $6^{\circ}$ o trabalho como um direito social do homem, as pessoas com deficiência ainda encontram muitas dificuldades para se inserirem neste mercado. De acordo com os dados do Ministério do Trabalho e Emprego (2012) em 2011, foram declarados 325.300 vínculos empregatícios de pessoas com deficiência (PCD), representando apenas $0,70 \%$ do total de vínculos gerais. Assim, considerando que 45.606.048 brasileiros, ou seja, 23,9\% da população total tem, segundo dados do IBGE (2010), algum tipo de deficiência, seja ela visual, auditiva, motora ou mental, torna-se evidente a exclusão do mercado de trabalho desta parcela populacional.

Para Bartalotti (2006), esta exclusão provém de uma ordem social legitimada por valores e ideologias enraizados na sociedade.
Ao longo da história as pessoas sempre foram agrupadas por categorias e aquelas que de certa forma não se encaixavam nos padrões estabelecidos eram excluídas ou segregadas. Esta situação ainda ocorre com vários grupos marginalizados, porém de forma velada e mascarada.

Para Sassaki (1997) e Bartalotti (2006), esta exclusão é fruto do estigma de que as pessoas com deficiência são doentes e incapazes de exercer a sua cidadania. Trata-se, portanto, da adoção do modelo médico da deficiência, no qual a pessoa é vista como dependente e inválida, precisando ser amparada e tutelada por terceiros. Esta concepção contribui significativamente para a resistência da sociedade em incluir pessoas com deficiência não só no mercado de trabalho, mas em todas as esferas sociais. O que se verifica com certa frequência são processos de integração de pessoas com deficiências leves em atividades laborais que não exijam modificações estruturais no local de trabalho.

Existe uma significativa diferença entre integração e inclusão. Para Sassaki (1997), enquanto na inclusão as pessoas com deficiência e a sociedade buscam, em parceria, equacionar problemas e efetivar a equiparação de oportunidades para todos, na integração, a pessoa com deficiência precisa superar as barreiras físicas, programáticas e atitudinais existentes para se integrar na sociedade. 
Assim, como a Lei 8.213/91 estabelece a obrigatoriedade de reserva de vagas para a pessoa com deficiência em empresas com mais de 100 funcionários, torna-se importante verificar se este processo de inserção está sendo inclusivista ou apenas integracionista. Desta maneira, o objetivo deste artigo foi verificar com base em um levantamento bibliográfico o panorama atual da inserção das pessoas com deficiência no mercado de trabalho no Brasil, verificando se a força da lei tem de fato papel inclusivo.

\section{Metodologia}

Trata-se de uma revisão de literatura com a temática de inclusão no mercado de trabalho das pessoas com deficiência.

Foi realizada uma busca nas bases de dados de acesso público SciELO, BIREME, descritores: Pessoa com Deficiência, Lei de Cotas, Integração, Inclusão e Mercado de Trabalho. Como estratégia para selecionar os artigos que comporiam a amostra deste estudo foram excluídos aqueles que tratavam da inclusão social das pessoas com deficiência sem relacioná-la ao mercado de trabalho, e foram incluídos os desenvolvidos após a implantação da Lei 8.213/91.

Foram selecionados 20 artigos que foram tabulados a fim de auxiliar as análises posteriores tendo em vista o objetivo deste artigo de revisão.

\section{Resultados}

Os registros coletados nos 20 artigos que compõe a amostra deste estudo estão tabulados na Tabela 1 por ordem cronológica de publicação.

LILACS e CAPES por meio dos seguintes

Tabela 1. Artigos que compõe a amostra deste estudo

\begin{tabular}{|c|c|c|c|}
\hline Artigo & Mét & & \\
\hline 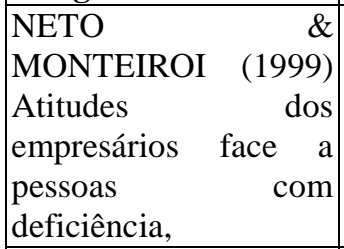 & $\begin{array}{l}1500 \text { empresas avaliadas } \\
\text { através de questionários } \\
\text { validados. }\end{array}$ & 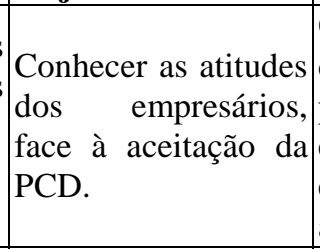 & $\begin{array}{l}\text { Os setores que melhor aceitam as PCD são os } \\
\text { de serviços, a hotelaria e o turismo. O seto } \\
\text { primário são os que piores aceitam. O } \\
\text { empresários mais jovens e com grau de } \\
\text { escolaridade mais elevados são os que melho } \\
\text { aceitam as PCD. }\end{array}$ \\
\hline $\begin{array}{l}\text { ARAÚJOSCHI\& } \\
\text { MIDT (2006) } \\
\text { A inclusão de pessoas } \\
\text { com necessidades } \\
\text { especiais no trabalho: } \\
\text { a visão de empresas e } \\
\text { de } \\
\text { educacionais especiais } \\
\text { na cidade de Curitiba }\end{array}$ & \begin{tabular}{|l} 
Foram avaliadas \\
empresas com quadro \\
funcional entre $111 \quad$ e \\
23.000 funcionários e \\
$10 \quad$ instituições \\
educacionais para PCD \\
através de entrevistas.
\end{tabular} & 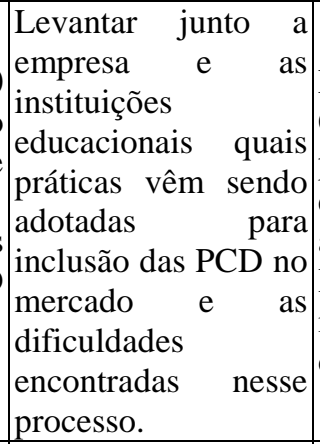 & $\begin{array}{l}\text { Empresas não conseguem cumprir a Lei d } \\
\text { Cotas, mas contratam por causa da su } \\
\text { pressão. O grande empecilho para contrataçãá } \\
\text { é a escolarização. As deficiências física } \\
\text { auditivas ou visuais são as mais contratada } \\
\text { Há um descompasso na relação empresa } \\
\text { instituições educacionais, pois não há un } \\
\text { diálogo produtivo que de fato favoreça a PCD }\end{array}$ \\
\hline $\begin{array}{lrr}\text { INO } \& & \text { CUNH } \\
2008) . & \text { Uma } & \text { questã } \\
\text { e cotas? } & \text { Com } \\
\text { essoas } & \text { con } \\
\text { eficiência } & \text { perceben }\end{array}$ & \begin{tabular}{|l} 
Foram avaliadas 49 PCD e \\
alunos de cursos de \\
capacitação profissional, \\
através de questionário
\end{tabular} & $\left|\begin{array}{lrr}\text { Verificar } & \text { o } & \text { que } \\
\text { pensam } & \text { as } & \text { PCD } \\
\text { sobre a sua inserção } \\
\text { no mercado } & \text { de } \\
\text { trabalho, } & & \text { após }\end{array}\right|$ & ação à capaci \\
\hline
\end{tabular}




\begin{tabular}{|c|c|c|c|}
\hline $\begin{array}{l}\text { sua inserção no } \\
\text { mercado de trabalho } \\
\text { com base em políticas } \\
\text { públicas de inclusão }\end{array}$ & & \begin{tabular}{|l|} 
obrigatoriedade \\
legal de contratar \\
empregados com \\
deficiência.
\end{tabular} & \\
\hline $\begin{array}{l}\text { FRAGA \& } \text { SOUZA } \\
(2009) \text {. Políticas } \\
\text { públicas para pessoas } \\
\text { com deficiência no } \\
\text { Brasil: o desafio da } \\
\text { inclusão social }\end{array}$ & \begin{tabular}{|lcrr|} 
Estudo & de & caráter \\
qualitativo & a & partir & de \\
pesquisa & \multicolumn{2}{c}{ bibliográfica. } \\
Análise & de & leis & com \\
políticas & públicas & para \\
PCD. & & & \\
\end{tabular} & $\mid \begin{array}{lrr}\text { Refletir } & \text { sobre } & \text { como } \\
\text { a } & \text { sociedade } \\
\text { brasileira } & \text { vem } & \text { se } \\
\text { comportando } & \text { em } \\
\text { relação } & \text { à } & \text { PCD, } \\
\text { tomando por base as } \\
\text { políticas públicas. }\end{array}$ & $\begin{array}{l}\text { O modo como a sociedade age em relação à } \\
\text { PCD é fruto de valores sociais. A existência da } \\
\text { legislação e o fortalecimento de importantes } \\
\text { organizações lideradas pelas próprias PCD } \\
\text { fortaleceram o novo debate sobre a } \\
\text { equiparação de oportunidades desse segmento. }\end{array}$ \\
\hline $\begin{array}{l}\text { FREITAS (2009). } \\
\text { Inserção e Gestão do } \\
\text { Trabalho de Pessoas } \\
\text { com Deficiência: um } \\
\text { estudo de caso }\end{array}$ & \begin{tabular}{|l}
80 gestores; 128 PCD; 5 \\
funcionários da gestão de \\
pessoas. \\
Questionário aos gestores; \\
e questionárior sobre \\
qualidade de vida às PCD.
\end{tabular} & 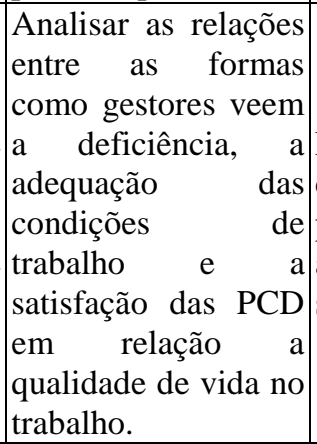 & $\begin{array}{l}\text { Ênfase na deficiência como impedimento ao } \\
\text { desempenho e à possibilidade de crescimento } \\
\text { profissional. A empresa faz questão de } \\
\text { associar seu nome ao de uma empresa } \\
\text { socialmente responsável. }\end{array}$ \\
\hline 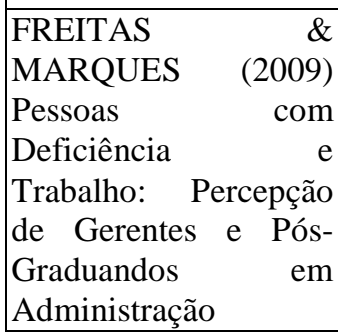 & 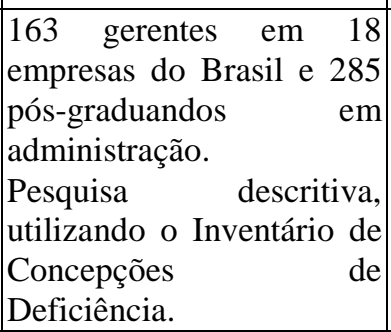 & \begin{tabular}{|lr} 
& \\
Avaliar & as \\
possibilidades & de \\
trabalho & para \\
pessoas & com \\
deficiência. & \\
&
\end{tabular} & $\begin{array}{l}\text { Não houve diferença significativa entre a } \\
\text { percepção a respeito das pessoas com } \\
\text { deficiência entre os grupos de gerentes de } \\
\text { pessoas com deficiência e alunos de } \\
\text { especialização em administração que não } \\
\text { trabalham com essas pessoas. }\end{array}$ \\
\hline $\begin{array}{lr}\text { GOULART } & \& \\
\text { JÚNIOR } & (2009) \text {. } \\
\text { Pessoas } & \text { com } \\
\text { deficiência } & \text { no } \\
\text { mercado de trabalho: } \\
\text { considerações sobre } \\
\text { políticas públicas nos } \\
\text { Estados Unidos, União } \\
\text { Europeia e Brasil }\end{array}$ & $\begin{array}{l}03 \text { instrumentos legais de } \\
\text { cada país. } \\
\begin{array}{l}\text { Análise das políticas } \\
\text { públicas de cada país. }\end{array}\end{array}$ & $\begin{array}{l}\text { Discutir aspectos das } \\
\text { políticas de emprego } \\
\text { adotados nos } \\
\text { Estados Unidos, na } \\
\text { União Europeia e no } \\
\text { Brasil para favorecer } \\
\text { a inserção das } \\
\text { no mercado de } \\
\text { trabalho. }\end{array}$ & $\begin{array}{l}\text { Embora as políticas guardem características } \\
\text { distintas, é notório o interesse na } \\
\text { implementação de ações para garantir a } \\
\text { participação das PCD no mercado de trabalho. }\end{array}$ \\
\hline $\begin{array}{l}\text { TOLDRÁ (2009). } \\
\text { Políticas afirmativas: } \\
\text { opinião das pessoas } \\
\text { com deficiência acerca } \\
\text { da legislação de } \\
\text { reserva de vagas no } \\
\text { mercado de trabalho }\end{array}$ & $\begin{array}{l}10 \text { pessoas com diferentes } \\
\text { tipos de deficiência física } \\
\text { e visual inseridas no } \\
\text { mercado de trabalho, em } \\
\text { Campinas-SP, em 2008. } \\
\text { Pesquisa } \\
\text { Entrevista e qualitativa. } \\
\text { Discurso }\end{array}$ & 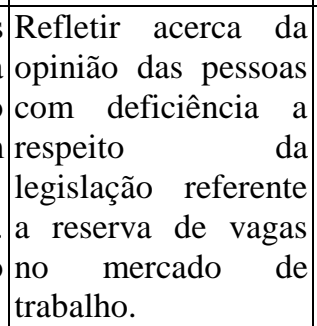 & $\begin{array}{l}\text { Indicam que a lei é considerada necessária, no } \\
\text { entanto, sua manutenção deve estar vinculada } \\
\text { ao grau de conscientização da sociedade como } \\
\text { um todo e à disponibilização de condições } \\
\text { objetivas para a inclusão laboral desta } \\
\text { população. }\end{array}$ \\
\hline $\begin{array}{lr}\text { ALMEIDA } & \& \\
\text { VELTRONE } & \\
(2010) \text { Perfil } & \text { da } \\
\text { pessoa } & \\
\text { deficiência } & \text { no } \\
\text { mercado de } & \text { trabalho } \\
\text { na cidade de } & \text { São } \\
\text { Carlos-SP } & \end{array}$ & $\begin{array}{lrr}92 & \text { funcionários } & \text { com } \\
\text { diferentes } & \text { tipos } & \text { de } \\
\text { deficiência de } & 04 \\
\text { empresas de São Carlos } \\
03 \text { representantes dos } \\
\text { recursos humanos e uma } \\
\text { enfermeira do trabalho. } \\
\text { Questionário estruturado } \\
\text { com perguntas abertas e } \\
\text { fechadas. }\end{array}$ & $\begin{array}{l}\text { Caracterizar } \\
\text { inserção da PCD no } \\
\text { mercado de trabalho } \\
\text { em relação ao tipo } \\
\text { de deficiência, nível } \\
\text { de escolaridade, } \\
\text { qualificação } \\
\text { profissional } \\
\text { ocupação atual. }\end{array}$ & $\begin{array}{l}\text { Tendências: empregar deficientes auditivos e } \\
\text { físicos, com menos comprometimento, para } \\
\text { menor reestruturação possível. Baixa } \\
\text { escolaridade das PCD e, para que possa ser } \\
\text { inserida, é preciso apresentar as qualidades } \\
\text { exigidas pelo trabalho, e demandar a menor } \\
\text { estruturação } \\
\text { possível. }\end{array}$ \\
\hline $\begin{array}{lr}\text { BAPTISTA } \& & \text { SILVA } \\
(2010) . & \text { Perfil }\end{array}$ & $\begin{array}{|llr|}\begin{array}{l}\text { Pessoas } \\
\text { denominam }\end{array} & \text { que } & \text { se } \\
\end{array}$ & 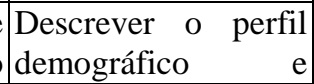 & $\begin{array}{l}\text { Além de quantificar e qualificar as pessoas } \\
\text { com deficiência do município de Belo }\end{array}$ \\
\hline
\end{tabular}




\begin{tabular}{|c|c|c|c|}
\hline $\begin{array}{l}\text { demográfico e r do } \\
\text { emprego das pessoas } \\
\text { com deficiência no } \\
\text { município de } \\
\text { Horizonte, Melo } \\
\text { Brasil }\end{array}$ & $\begin{array}{l}\text { portadoras de algum tipo } \\
\text { de deficiência em Belo } \\
\text { Horizonte MG. } \\
\text { Estudor descritivo. } \\
\text { Informações demográficas } \\
\text { e socioeconômicas do } \\
\text { banco de dados do Censo } \\
\text { de } 2000,(\text { IBGE). }\end{array}$ & $\begin{array}{l}\text { socioeconômico de } \\
\text { pessoas com } \\
\text { deficiência na cidade } \\
\text { de Belo Horizonte, } \\
\text { Minas Gerais. }\end{array}$ & $\begin{array}{l}\text { Horizonte, o estudo possibilitou identificar } \\
\text { falhas nos sistemas educacionais e de saúde } \\
\text { que precisam ser corrigidas e transformadas } \\
\text { para maior inclusão dessas pessoas. }\end{array}$ \\
\hline $\begin{array}{lr}\text { LIMA, } & \text { SILVA, } \\
\text { GALVÃO, } & (2010) . \\
\text { percepção } & \text { dos } \\
\text { empregadores } & \text { sobre a } \\
\text { admissão } & \text { de } \\
\text { trabalhadores } & \text { com } \\
\text { Síndrome de Down } & \\
\end{array}$ & $\begin{array}{l}\text { Administradores de } 3 \\
\text { empresas, localizadas na } \\
\text { cidade de Santos, com } \\
\text { portadores de Síndrome de } \\
\text { Down. } \\
\text { Entrevista } \\
\text { semiestruturada. }\end{array}$ & \begin{tabular}{|l} 
Analisar o ponto de \\
vistar \\
empregadores \\
quanto à contratação \\
do portador de de \\
Síndrome de Down. \\
\end{tabular} & $\begin{array}{l}\text { Necessidade de deixar de encarar a inclusão } \\
\text { como uma obrigação legal, sendo fundamental } \\
\text { reconhecer as reais capacidades, competências } \\
\text { e habilidades da PCD. Não basta apenas } \\
\text { profissionalizar a PCD, mas mudar } \\
\text { comportamentos. }\end{array}$ \\
\hline $\begin{array}{lr}\text { TOLDRÁ } & \& \\
\text { BRUNELLO } & (2010) . \\
\text { Desafios para a } \\
\text { inclusão no mercado } \\
\text { de trabalho de pessoas } \\
\text { com } \quad \text { deficiência } \\
\text { intelectual: } \\
\text { experiências } \\
\text { construção }\end{array}$ & $\begin{array}{l}4 \text { Instituições } \\
\text { especializadas para PCD } \\
\text { intelectual em Campinas, } \\
\text { sendo: 1 representante de } \\
\text { cada instituição, } \\
\text { terapeutas ocupacionais, 1 } \\
\text { psicólogo, 1 coordenador } \\
\text { da instituição e } \\
\text { assistente social. } \\
\text { Entrevista com roteiro de } \\
\text { perguntas } \\
\text { semiestruturadas }\end{array}$ & 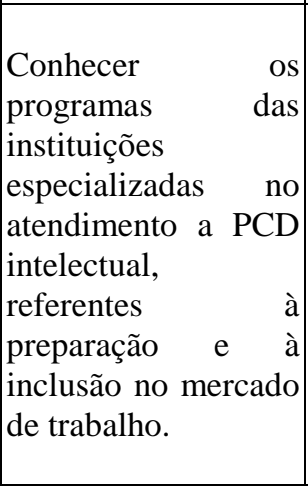 & $\begin{array}{l}\text { Há necessidade de adequação das propostas } \\
\text { das instituições especializadas às exigências } \\
\text { do mercado de trabalho e à realidade social. O } \\
\text { acompanhamento e suporte contribuem para a } \\
\text { contratação e permanência da PCD intelectual } \\
\text { no mercado de trabalho. }\end{array}$ \\
\hline $\begin{array}{l}\text { VASCONCELOS } \\
\text { (2010). O trabalhador } \\
\text { com deficiência e as } \\
\text { práticas de inclusão no } \\
\text { mercado de trabalho } \\
\text { de Salvador, Bahia }\end{array}$ & $\begin{array}{l}35 \text { pessoas, sendo: } 22 \\
\text { trabalhadores rom } \\
\text { deficiência, } 6 \text { chefes ou } \\
\text { colegas de trabalho desses } \\
\text { deficientes, } 7 \text { técnicos ou } \\
\text { dirigentes de instituições } \\
\text { relacionadas à deficiência. } \\
\text { Estudo exploratório. } \\
\text { Roteiros de entrevistas } \\
\text { semiestruturadas } \\
\end{array}$ & 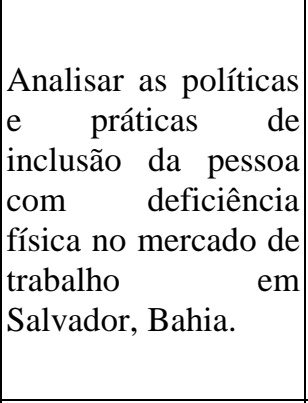 & $\begin{array}{l}\text { O desenvolvimento de uma política pública de } \\
\text { inclusão no trabalho exige não apenas a } \\
\text { implementação do sistema de cotas, mas um } \\
\text { conjunto de medidas que envolvam a inclusão } \\
\text { escolar, o estímulo à habilitação e ao } \\
\text { desenvolvimento profissional. }\end{array}$ \\
\hline $\begin{array}{l}\text { MONTEIRO (2011). } \\
\text { Responsabilidade } \\
\text { social empresarial: } \\
\text { inclusão de pessoas } \\
\text { com deficiência no } \\
\text { mercado de trabalho }\end{array}$ & 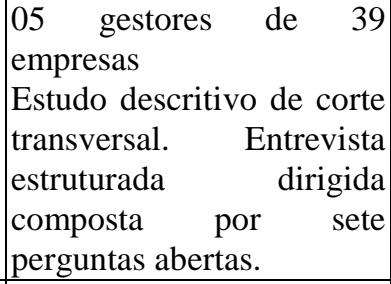 & $\begin{array}{lr}\text { Investigar } & \mathrm{a} \\
\text { existência } & \mathrm{de} \\
\text { empresas } & \text { que } \\
\text { atuavam } & \text { em } \\
\text { lonformidade } & \text { com } \mathrm{a} \\
\text { lei } & \end{array}$ & $\begin{array}{l}\text { Necessidade de criação de programas para (re) } \\
\text { ciclagem dos gestores, profissionalização das } \\
\text { PDs e políticas públicas mais incisivas no } \\
\text { processo de inclusão. }\end{array}$ \\
\hline $\begin{array}{l}\text { LEITE,VIOLANTE, } \\
(2011) \text {. } \\
\text { empregabilidade das } \\
\text { pessoas rom } \\
\text { deficiência: r uma } \\
\text { análise da inclusão } \\
\text { social no mercado de } \\
\text { trabalho do município } \\
\text { de Bauru, SP } \\
\end{array}$ & $\begin{array}{l}\text { Funcionários do setor de } \\
\text { recursos humanos de } 12 \\
\text { empresas de médio e } \\
\text { grande porte no município } \\
\text { de Bauru-SP. } \\
\text { Roteiro de entrevista } \\
\text { semiestruturado, contendo } \\
13 \text { questões. }\end{array}$ & $\begin{array}{lr}\text { Examinar } & a \\
\text { empregabilidade } & \text { das } \\
\text { PCD } & \text { em } \\
\text { atendimento } & \text { ao } \\
\text { decreto 3298, que } \\
\text { estabelece cotas para } \\
\text { contratação de PCD. }\end{array}$ & $\begin{array}{l}\text { As empresas não cumprem a Lei de Cotas, } \\
\text { mas contratam por causa da pressão da } \\
\text { referida Lei e selecionam pelas deficiências } \\
\text { menos "comprometedoras" ou aquelas que } \\
\text { supostamente são favoráveis para as linhas de } \\
\text { produção. }\end{array}$ \\
\hline $\begin{array}{lr}\text { LEÃO, } & \text { SILVA, } \\
(2012) \text {. Vivências } & \text { de } \\
\text { trabalhadores } & \text { com } \\
\text { deficiência: } & \text { uma } \\
\text { análise à luz } & \text { da } \\
\text { Psicodinâmica } & \text { do } \\
\end{array}$ & $\begin{array}{llr}4 \text { deficientes auditivos e } & 2 \\
\text { deficientes físicos. } & \\
\text { Pesquisa } & \text { qualitativa } & \text { por } \\
\text { meio de } & 6 \text { estudos } & \text { de } \\
\text { casos. } & \text { Entrevistas } & \text { e } \\
\text { análise de conteúdo à luz }\end{array}$ & $\begin{array}{lrr}\text { Investigar } & \text { as } \\
\text { vivências } & \text { subjetivas } \\
\text { de } & \text { deficientes } \\
\text { auditivos e físicos de } \\
\text { uma } & \text { empresa } & \text { no } \\
\text { Vale } & \text { do } & \text { Paraíba }\end{array}$ & $\begin{array}{l}\text { Os resultados apontaram aspectos de } \\
\text { sofrimento no trabalho oriundos do desgaste } \\
\text { físico ou psíquico e da falta de } \\
\text { reconhecimento no trabalho, que reativam } \\
\text { estratégias defensivas frente a situações } \\
\text { adversas. }\end{array}$ \\
\hline
\end{tabular}




\begin{tabular}{|c|c|c|c|}
\hline Trabalho. & $\begin{array}{l}\text { da Psicodinâmica do } \\
\text { Trabalho. }\end{array}$ & Paulista. & \\
\hline $\begin{array}{l}\text { PEREIRA, } \\
\text { PASSERINO, (2012). } \\
\text { Um estudo sobre o } \\
\text { perfil dos empregados } \\
\text { com deficiência em } \\
\text { uma organização }\end{array}$ & $\begin{array}{lrrr}\text { Organização } & \text { de } & \text { grande } \\
\text { porte do } & \text { ramo } & \text { da } \\
\text { alimentação. } & & \text { Recorte } \\
\text { quantitativo. } & & \text { Dados } \\
\text { coletados e } & \text { documentos } \\
\text { disponibilizados } & \text { pela } \\
\text { empresa } & \text { e } & \text { seus } \\
\text { funcionários, } & \text { além } & \text { de } \\
\text { documentos } & & \text { oficiais } \\
\text { nacionais. } & & \end{array}$ & $\begin{array}{|lrr|}\text { Identificar } & \text { o } & \text { perfil } \\
\text { dos empregados } & \text { com } \\
\text { deficiência } & \text { em } & \text { uma } \\
\text { organização } & \text { de } \\
\text { grande } & \text { porte } & \text { do } \\
\text { ramo da alimentação } \\
\text { a fim de discutir o } \\
\text { contexto social no } \\
\text { qual estão inseridos. }\end{array}$ & $\begin{array}{l}\text { O Benefício Previdenciário (BPC) influencia a } \\
\text { inclusão de PCD no mercado de trabalho. A } \\
\text { baixa escolarização está ligada à baixa } \\
\text { remuneração e faz as PCD preferirem o BPC. } \\
\text { É preciso educar e qualificá-las no mercado de } \\
\text { trabalho, mas também é fundamental educar as } \\
\text { organizações e sociedades para esta inclusão. }\end{array}$ \\
\hline $\begin{array}{ll}\text { LIMA (2013). O } \\
\text { sentido do trabalho } \\
\text { para pessoas com } \\
\text { deficiência }\end{array}$ & 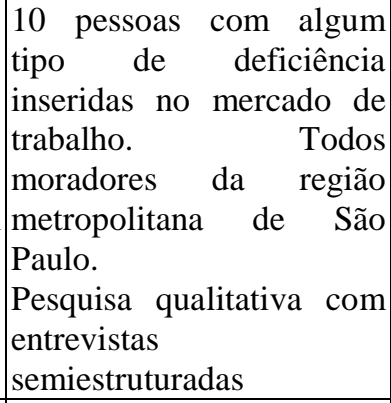 & \begin{tabular}{|lr} 
& \\
Analisar o & sentido \\
do trabalho & para as \\
pessoas & com \\
deficiência. & \\
& \\
\end{tabular} & $\begin{array}{l}\text { O trabalho tem grande importância na vida das } \\
\text { PCD, não apenas pelo seu caráter } \\
\text { instrumental, de ganho material, mas também } \\
\text { por aspectos subjetivos, como o sentimento de } \\
\text { ser importante. Os múltiplos sentidos } \\
\text { atribuídos ao trabalho são de experiências e } \\
\text { vivências propiciadas pelo seu encontro com } \\
\text { esta realidade. }\end{array}$ \\
\hline $\begin{array}{lr}\text { GARCIA } & (2014) . \\
\text { Panorama da } & \text { Inclusão } \\
\text { das Pessoas } & \text { com } \\
\text { deficiência } & \text { no } \\
\text { mercado de } & \text { trabalho } \\
\text { no Brasil } & \end{array}$ & $\begin{array}{l}\text { PCD em idade produtiva, } \\
\text { declaradas no censo do } \\
\text { IBGE. Estudo descritivo } \\
\text { com análise quantitativa e } \\
\text { qualitativa dos dados do } \\
\text { senso do IBGE e dos } \\
\text { dados obtidos na RAIS. }\end{array}$ & $\begin{array}{l}\text { Traçar um panorama } \\
\text { recente do acesso ao } \\
\text { mercado formal de } \\
\text { trabalho das pessoas } \\
\text { com deficiência no } \\
\text { Brasil. }\end{array}$ & $\begin{array}{l}\text { Em média, } 316 \text { mil PCD estiveram inseridas } \\
\text { formalmente no mercado de trabalho no } \\
\text { período considerado. A população com } \\
\text { deficiência em idade produtiva é de } \\
\text { aproximadamente } 6,5 \text { milhões de pessoas. } \\
\text { Percebe-se o quão baixa é a participação deste } \\
\text { segmento no trabalho formal }\end{array}$ \\
\hline
\end{tabular}

\section{Discussão}

Foram selecionados 19 artigos nacionais e 01 internacional (Portugal), publicados entre 1999 e 2014. Todos os nacionais evidenciaram a importância da Lei 8.213/91 no que tange à inserção no mercado de trabalho das pessoas com deficiência, resultando em uma descrição detalhada do impacto desta política na sociedade.

Evidenciou-se um elevado número de pesquisas qualitativas (40\%), o que pode significar um maior direcionamento das pesquisas para os aspectos de percepção, tanto das pessoas com deficiência, quanto da comunidade em que estão inseridas, visando avaliar a sua aceitação pessoal e social. Oito artigos avaliaram através de entrevistas e questionários os gestores, sete avaliaram as pessoas com deficiência e três avaliaram as duas visões integradas. Estes achados estão de acordo com a visão global defendida por Sassaki (1997) na qual para que ocorra inclusão, a sociedade e a pessoa com deficiência precisam enfrentar juntas os desafios de conviverem com a diversidade. (SASSAKI, 1997).

Outro dado importante foi a grande concentração de pesquisas nas regiões sul e sudeste $(65 \%)$ do Brasil. Acredita-se que isto ocorra devido à concentração populacional, empresarial e comercial nestes centros. Neste contexto, tornam-se necessárias pesquisas em outras regiões brasileiras, principalmente no nordeste, que, segundo dados do IBGE (2010), 
apresenta a maior incidência de pessoas com deficiência $(26,3 \%)$.

É importante ressaltar também que a associação entre empregabilidade e nível de escolaridade foi descrita em 35\% dos artigos, revelando dificuldades encontradas pelos gestores na contratação de pessoas com deficiência devido à baixa capacitação profissional. Evidencia-se, inclusive, que as pessoas com deficiência com maior nível de escolaridade conseguem inserção no mercado de trabalho, enquanto as que possuem baixa escolaridade têm maior dificuldade para serem contratadas e permanecerem empregadas, além de possuírem menor remuneração.

Para Araújo e Schmidt (2006), as pessoas com deficiência, ao serem excluídas do processo educacional, são privadas de uma série de bens culturais e intelectuais os quais dificultam o processo de inclusão trabalhista e social. Assim, tendo em vista estas circunstâncias, torna-se imprescindível que cada vez mais as pessoas com deficiência tenham acesso ao sistema educacional, de forma que a transição da escola para o trabalho ocorra naturalmente. Além disso, fica evidente a necessidade da associação entre instituições educacionais e empresas para melhor capacitação das pessoas com deficiência de forma a atender às demandas do mercado de trabalho.

Os dados obtidos nos artigos analisados revelam também a visão de que pessoas com deficiência são, na grande maioria das vezes, admitidas e contratadas desde que tenham qualificação profissional e consigam utilizar os espaços físicos e equipamentos das empresas sem nenhuma modificação. Trata-se, portanto, conforme proposto por Sassaki (1997), de uma integração e não inclusão.

Cabe salientar ainda que $40 \%$ dos artigos apontam para a contratação de pessoas com deficiências leves de forma que a sua inserção tenha um impacto pequeno na produção e nas alterações estruturais para acessibilidade. Assim, a legislação é cumprida, porém não há uma conscientização quanto à importância da inclusão efetiva destas pessoas (VASCONCELOS, 2010).

Por fim, apesar de importância da Lei de Cotas ser verificada em $50 \%$ dos artigos, todos admitem que, se não houvesse a necessidade legal de contratação das pessoas com deficiência, este grupo estaria fora do mercado de trabalho. Assim, embora ainda não haja a percepção da importância social do trabalho na construção da cidadania da pessoa com deficiência, a legislação é importante para introduzir esta convivência e, a partir dela, compreender a força do trabalho e da capacidade laboral das pessoas com deficiência, levando a uma aceitação cada vez maior por meio do convívio com a diversidade.

\section{Conclusão}


Os resultados encontrados revelam que, apesar dos esforços para inclusão das pessoas com deficiência no mercado de trabalho, o caminho para inserção ainda está repleto de barreiras no que tange à aceitação da sociedade. A situação atual revela uma sociedade ainda preconceituosa e não inclusivista. A pessoa com deficiência precisa ser capaz de superar barreiras físicas, programáticas, atitudinais e culturais para se inserir no mercado de trabalho. A lei de cotas é fundamental para garantir o acesso da pessoa com deficiência no mercado de trabalho, mas não assegura a sua real inclusão.

Por fim para que a inclusão realmente ocorra é imprescindível que haja um processo bilateral, no qual a sociedade ofereça condições para que as pessoas com deficiência exerçam a sua cidadania, com direitos a serem preservados e deveres a serem cumpridos, e as pessoas com deficiência busquem maior autonomia, independência a fim de que consigam participar ativamente da sociedade.

\section{Referências}

ALMEIDA, M. A.; VELTRONE, A. A. Perfil da pessoa com deficiência no mercado de trabalho na cidade de São Carlos-SP. Revista Educação Especial, v. 23, n. 36, jan./abr. 2010. ARAÚJO, J. P.; SCHIMIDT, A. A inclusão de pessoas com necessidades especiais no trabalho: a visão de empresas e de instituições educacionais especiais na cidade de Curitiba. Revista Brasileira Educação Especial, v.12, n.2, p.241-254, maio/ago. 2006.
AREOSA, A. L. Competitividade organizacional e os portadores de necessidades especiais: a função e o desempenho laboral destes atores no interior da indústria do fumo e de instituições financeiras. Barbarói, n. 30, jan./jul. 2009.

BAPTISTA, A. K.; SILVA, F. C. M. Perfil demográfico e do emprego das pessoas com deficiência no município de Belo Horizonte, MG - Brasil. Revista Médica de Minas

Gerais, v. 21, n. 3, 2010.

BARTALOTTI, C. C. Inclusão social das pessoas com deficiência: utopia ou possibilidade? São Paulo: Paulus, 2006.

\section{BRASIL. Constituição da República}

Federativa do Brasil. Brasília (DF): Senado, 1988.

. Lei n.8.213/91, de 24 de julho de 1991. Dispõe sobre os planos de benefícios da Previdência Social e dá outras providências. Brasília (DF), 1991.

. Ministério do Trabalho e Emprego.

Relação Anual de Informações Sociais (RAIS).

FRAGA, M. N. O.; SOUZA, A. F. Políticas públicas para pessoas com deficiência no Brasil: o desafio da inclusão social. Revista Eletrônica de Enfermagem, v. 11, n. 2, p. 418-423, maio 2009.

FREITAS, M. N. C. Inserção e Gestão do Trabalho de Pessoas com Deficiência: um estudo de caso. RAC, v. 13, ed. esp., p. 121138, jun. 2009.

FREITAS, M. N. C.; MARQUES, A. L. Pessoas com Deficiência e Trabalho: Percepção de Gerentes e Pós-Graduandos em Administração. Psicologia Ciência e Profissão, v. 29, n. 5, p. 244 - 257, fev. 2009.

GARCIA, V. G. Panorama da Inclusão das Pessoas com deficiência no mercado de trabalho 
no Brasil. Trabalho, Educação e Saúde, v. 12, n. 1, jan./abr. 2014.

IBGE. Instituto Brasileiro de Geografia e Estatística. Censo Demográfico 2010:

Características Gerais da População, religião e pessoas com deficiência. Rio de Janeiro, 2010.

LEÃO, M. A. B. G.; SILVA, L. S. Vivências de trabalhadores com deficiência: uma análise à luz da Psicodinâmica do Trabalho. Revista

Brasileira de Saúde Ocupacional, v. 37, n. 125, p. 159-169, jan/jun. 2012.

LEITE, L. P.; VIOLANTE, R. R. A empregabilidade das pessoas com deficiência: uma análise da inclusão social no mercado de trabalho do município de Bauru, SP. Cadernos de psicologia social do trabalho, v. 14, n. 1, p. 73 - 91, jun. 2011.

LIMA, J. P.; SILVA, T. B.; GALVÃO, E. C. F. A percepção dos empregadores sobre a admissão de trabalhadores com Síndrome de Down. Revista de Enfermagem do Curso de Enfermagem da Universidade Paulista, v. 28, n. 1, p. 17-20, 2010.

LIMA, M. P. et al. O sentido do trabalho para pessoas com deficiência. Revista

Administração Mackenzie, v. 14, n. 2, p. 42 68, mar/abr. 2013.

LINO, M. V.; CUNHA, A. C. B. Uma questão de cotas? Como pessoas com deficiência percebem sua inserção no mercado de trabalho com base em políticas públicas de inclusão.

Pesquisas e Práticas Psicossociais, v. 3, n. 1, p. 65 - 74, ago. 2008.

MANUELA NETO, M.; MONTEIRO, I. Atitudes dos empresários face a pessoas com deficiência. Repositório Institucional Universidade do Algarve, maio 1999.

MONTEIRO, L. G. et al.; Responsabilidade social empresarial: inclusão de pessoas com deficiência no mercado de trabalho. Revista Brasileira de Educação Especial, v.17, n.3, p. 459-480, set./dez., 2011.
OLIVEIRA, M.; GOULART JÚNIOR, E.; FERNANDES, J. M. Pessoas com deficiência no mercado de trabalho: considerações sobre políticas públicas nos Estados Unidos, União Europeia e Brasil. Revista Brasileira Educação Especial, v.15, n.2, p. 219-232, maio/ago. 2009.

PEREIRA, A. C. C.; PASSERINO, L. Um estudo sobre o perfil dos empregados com deficiência em uma organização. Revista Brasileira Educação Especial, v.18, n.2, p. 245-264, abr./jun., 2012.

SAMPAIO, R. F.; MANCINI, M. C. Estudos de revisão sistemática: um guia para síntese criteriosa da evidência científica. Revista brasileira de fisioterapia, v. 11, n. 1, p. 83 89, jan./fev. 2007

SASSAKI, R. K. Inclusão: construindo uma sociedade para todos. 1 ed. Rio de Janeiro: WVA, 1997.

TOLDRÁ, R. C; DE MARQUE, C. B.; BRUNELLO, M. I. B. Desafios para a inclusão no mercado de trabalho de pessoas com deficiência intelectual: experiências em construção. Revista Terapia Ocupacional Universidade de São Paulo, v. 21, n. 2, p. 158165, maio/ago. 2010.

TOLDRÁ, R. C. Políticas afirmativas: opinião das pessoas com deficiência acerca da legislação de reserva de vagas no mercado de trabalho.

Revista Terapia Ocupacional Universidade de São Paulo, v. 20, n. 2, p. 110-117, maio/ago. 2009.

VASCONCELOS, F. D. O trabalhador com deficiência e as práticas de inclusão no mercado de trabalho de Salvador, Bahia. Revista Brasileira Saúde Ocupacional, v. 35, n. 121, p. 41-52, mar. 2010. 